\title{
Characterizing Ethical Decision-Making and Its Influences - Examining Higher Education Leaders in Poland
}

\author{
Tara Shollenberger (High Point University in High Point, North Carolina)
}

\section{Introduction}

Leaders in higher education have a "higher" and more transparent ethical responsibility than other leaders due in part to the increasingly important role that higher education is taking to positively influence individuals, organizations, and societies, as well as the impact that international growth of educational institutions is having on leadership (Shapiro \& Stefkovich 2011). Thus, how leaders from different cultures make ethical decisions provides an opportunity to better understand how important decisions concerning morals and ethics are made. The ethical decision-making process that administrators use not only affects them personally, but it can also impact staff, faculty, students, parents, communities, and the overall ethical climate of the organization (Starrat 2004) and can even have an impact on communities and societies (Hatcher \& Aragon 2000). The rapid growth of technology as well as changes in socio-political landscapes and subsequent growth of globalization have ensured that unethical behaviors and scandals (Resick, Hanges, Dickson, \& Mitchelson 2006) are felt "immediately in other parts of the world" (Martin, Resick, Keating, \& Dickson 2009, 127).

Ethical decision-making is not simply the procedure used by a leader to make a decision; it is the process by which human values are put into action. There are a myriad of human values that differ from culture to culture (Carrithers 1992; Ciulla 1998a). Cultural values are one aspect of leadership that helps the leader to define ethics within their "home" culture (Ciulla 1998a). However, the rise of globalization has created the need for a more comprehensive perspective for understanding ethical values and ethical decision-making practices. To be globally effective, leaders must be aware of the ethical similarities and differences across and within cultures that could influence their practice. Previous cross-cultural studies on EDM have focused primarily on gender differences, which indicated that females, regardless of culture, showed a higher intention to act more ethically than their male counterparts (Cohen et al. 2001; Valentine \& Rittenburg 2007). Globalization 
has set the stage so that "the primary venue for ethical debates in the future will more and more be the world stage" (Carroll 2004, 114). Thus, there is a need to have a clear understanding of the demands and challenges of ethical decision-making "across cultural boundaries, which, in turn, necessitates an understanding of beliefs about... [ethical decision-making] in different cultures" (Martin et al. 2009, 127). Both Jackson (2001) and Brown and Treviño (2006) observed a lack of empirical study of cross-cultural differences in ethical decision-making in addition to a lack of cultural explanation for different perspectives between various countries.

Poland was selected for this study because Poland and the United States have a long history of cross-national partnerships and strategic alliances (Polish-American Chamber of Commerce of the Southeast United States [PACC-South] 2013). Currently, Poland is America's largest trading partner in Central Europe (Blank 2012). In fact, U.S. companies like UPS, Credit Suisse, Hewlett-Packard, Dell, Google, Intel, and Motorola have played key roles in fostering Poland's market-driven economy by opening offices in Poland employing over 180,000 Polish citizen and investing over $\$ 30$ billion (Blank 2012). In addition, Poland is one of Europe's fastest growing economies and much interest has been created in building stronger ties with the U.S. (Sheets 2012). As stated by acting Commerce Secretary Rebecca Blank in the closing remarks of the U.S.-Poland Business Summit in Warsaw, Poland in June 2012, "Poland-with its educated workforce, strategic location, and other key-assets -is poised to be one of the next great global hubs of innovation" (Blank 2012, para. 23). However, it must be noted that Poland is still a relatively a new democratic country having previously been a Communist nation until 1989.

Polish higher education systems are experiencing their own unique struggles; many universities in Poland are overregulated. As of 2008, over 700 legal regulations dictated educational policies. There was a perceived low quality of education, lack of national and global recognition, increasing numbers of graduates who were unable to find employment, and severe budget constraints (Thieme 2012). In previous years, the government exerted control over academic governance mandating that higher education institutions admit large numbers of students thus crowding classrooms while simultaneously placing restrictions on university faculty salaries that were well below European Union faculty wages (Thieme 2012). In 2013, after a slow recovery to an economic decline, 38 of the 95 higher education institutions in Poland experienced profit losses totaling 21.3 million Euros. It is estimated that Polish institutions will have 800,000 fewer students over the next seven years, a decline from the 1.9 million that were registered in 2012 representing a 40\% drop in student numbers ("Poland's Universities" 2013). Higher education administrators in Poland are under tremendous pressures that may impact decisions they make about students, staff, faculty, and the university as a whole (Thieme 2012). These circumstances create a need to 
better understand how higher education administrators of Polish universities make value based and ethical decisions before high profile scandals like those in the U.S. affect their institutions.

In conclusion, the literature on ethical decision-making revealed several variables that impacts EDM. With the research focused on these individualistic and innate variables a significant gap in the literature has emerged in reference to environmental influences on ethical decision-making practices within higher education. Environmental factors are pliable and can be changed routinely unlike age or gender thus creating a need for organizations to always be aware of these ever-changing variables. The focus of this research was to explore ethical decision-making of academic leaders in Poland by first defining EDM. It is important to provide a specific EDM definition as related to the field of education to help guide academic leaders within the field. Previous definitions have been spread across various disciplines which can be vague or not related to the issues or situations that higher education leaders are faced with. Then the environmental factors that influence EDM and the processes that leaders use to make ethical decisions where explored. Current models were all developed in the field of business in order to better understand business concepts such as marketing and sales. These models were examined and common components among the six EDM models were identified and used with participants to create a new model. No current model exists that focuses specifically on education and those specific areas faced by higher education administrators. Additionally, these models are created with components developed within the United States and do not account for crosscultural interpretations or applicability. Recent pressures and constraints placed on leaders offer a timely opportunity to examine how they perceive their ethical decision-making and an opportunity for researchers and practitioners to better understand the practices and processes that leaders use.

\section{Models}

Several response process models were constructed to help leaders gain insights into the complexity of EDM (Sen \& Vinze 1997). Of the models developed, the following six models are the most referenced EDM models located in the related literature. All these models were developed within the field of business to examine concepts such management, sales, and marketing. These six models have been established and validated and have been used and cited in other fields of academia beyond the business field; however, it is important that a model be developed that is specific to higher education and the unique challenges that pertain to that field. The six models are: 1) The Four Component Model (Rest 1986), 2) Contingency Model of Ethical Decision 
Making in a Marketing Organization (Ferrell \& Gresham 1985), 3) Model for Analyzing Ethical Decision-Making in Marketing (Dubinsky \& Loken 1989), 4) Model of Ethical Decision Making (Hunt \& Vitell 1986), 5) Issue-Contingent Model of Ethical Decision Making in Organizations (Jones 1991), and 6) Interactionist Model of Ethical Decision Making in Organizations (Treviño 1986).

Each of the six models is slightly different in make-up which reflects differences in leaders' perspectives. After examination of the aforementioned models, the following ten components were identified as important. The ten components are: recognition of the ethical issue (Ferrell \& Gresham 1985; Hunt \& Vitell 1986; Jones 1991; Rest 1986; Treviño 1986), stages of moral development (Jones 1991; Rest 1986; Treviño 1986), environmental factors (internal) (Ferrell \& Gresham 1985; Hunt \& Vitell 1986; Jones 1991; Treviño 1986), environmental (external) (Ferrell \& Gresham 1985; Hunt \& Vitell 1986; Jones 1991; Treviño 1986), individual moderators (Ferrell \& Gresham 1985; Hunt \& Vitell 1986; Jones 1991; Treviño 1986), moral intensity (Jones 1991), evaluation of behavior (Dubinsky \& Loken 1989; Ferrell \& Gresham 1985; Hunt \& Vitell 1986; Jones 1991; Rest 1986), moral decision-making (Ferrell \& Gresham 1985; Jones 1991; Rest 1986), engagement in moral behavior (Dubinsky \& Loken 1989; Ferrell \& Gresham 1985; Hunt \& Vitell 1986; Jones 1991; Rest 1986; Treviño 1986), and consequences (Dubinsky \& Loken 1989; Ferrell \& Gresham 1985; Hunt \& Vitell 1986; Jones 1991).

\section{Statement of the Problem}

Current literature identifies ten different definitions for ethical decisionmaking within various fields of study such as philosophy, business, and education. The diversity of definitions creates a lack of cohesion and continuity especially within the growing global work environment. A specific definition is needed to help guide those administrators within higher education.

Treviño and Youngblood (1990) found that something within the organizational environment misleads otherwise good employees to exhibit unethical behaviors supporting the need for experts as defined by the Delphi Method to identify important environmental factors that impact ethical decision-making. Previous EDM research found significance in individual variables such as gender, age, personality, and cultural. These variables while important expose a significant gap in the literature in reference to environmental influences on ethical decision-making practices. Environmental influences are variables unlike gender and age which can be manipulated and are constantly changing. This creates a hardship on employers as these are not static variables. This gap is even more apparent within the context of higher education and across cultures. More needs to be understood about 
environmental influences on the processes used to make ethical decisions. Currently, there are multiple EDM process models identified in the literature. The six most referenced models were developed and used within business and industry. No EDM process model was located that was developed or used in higher education, and no models were located that sought to identify differences in leaders' perspectives of specific components of EDM process models in order to develop a cross-cultural EDM process model.

If leaders better understand the cause-and-effect specific components are having on their decisions on how to address ethical dilemmas, then those decisions may result in positive results that have the potential to nurture an ethical work environment (Treviño \& Youngblood 1990). In addition, if environmental factors are identified, these variables can be critical for leaders who work in multi-cultural environments. Therefore, this study examined the various definitions of EDM in order to identify a specific definition that applies to the field of higher education. Additionally, this study identified environmental factors that influence the EDM processes used by university leaders in Poland. Finally, an EDM process model was refined and developed and agreed upon by leaders in Poland. Creating a new process of ethical decision-making which can be used with each specific population rather than relying on a model that was created for a different area and for Polish leaders a different culture.

\section{Research Questions}

The study was exploratory in nature using a review of literature and the Delphi Method to collect and synthesize expert knowledge through an Internet-based data collection format. In addition, the Delphi Method was used to create a new model of EDM, for participants in Poland. Three research questions guided the study. The research questions were used to 1) identify how ethical decision-making was defined by leaders in higher education within Polish universities and 2) to identify top environmental factors they felt were important. The third research question asked participants to develop an EDM model using 10 pre-established components from the EDM literature and come to a consensus on a new process model they believed was important in carrying out ethical decision-making for higher education administrators in Poland.

Research Question 1

To what extent was there a consensus on a definition of ethical decision-making among a Delphi panel of subject matter experts (SMEs) representing leadership in higher education in Poland? 
Research Question 2

Was there consensus on the top environmental factors that they believed important for ethical decision-making among the Delphi panel of experts representing leadership in higher education in Poland?

Research Question 3

Was there consensus among the Delphi panel of experts representing leadership in higher education in Poland in making choices about identifying and connecting the multiple process components of ethical decision-making models, and if no consensus was reached what differences in choices of model components existed?

\section{Theoretical Framework}

For the purpose of this study, both middle-range and substantive theories were used to establish the theoretical framework. Creswell (2009) describes a middle-range or meso-level theories that link the micro and macro level theories. A middle-range or meso-level is defined as theories of organization, social movement, or community, and macro level theories are defined as providing explanations for larger institutions like social institutions, cultural systems, or whole societies. Substantive theories, on the other hand, "offer explanations in more restricted settings and are limited in scope, often being expressed as propositions or hypotheses" (Camp 2001, 3) for example, as used in case studies. In addition, Bartlett states that "the lack of a coherent theoretical framework which is able to embrace the complexities of organizational reality at these multiple levels of analysis constitutes a problem for the field in terms of ... ethical research and theorizing" $(2003,225)$. Therefore, several substantive theories were proposed as theoretical frameworks which were used to guide this study in an attempt to embrace the complexities of the reality of ethical decision-making. However, using a Delphi study limits the generalization of findings, thus offering a more limited scope as in the case of a substantive theory. The first proposed substantive theory was categorized as "Socialization and Learning". Socialization supports the importance of the organizational or business environment (Schein 1990). Learning as a theoretical framework is synthesized from the theories of social learning and the power of context (Gladwell 2000). Learning supports the importance of how people teach, learn, and model other people and environments (Bandura 1977), in this specific instance, work environments. Learning couples with Socialization in explaining environmental factors within a business environment. Socialization and Learning explain how environmental factors like leaving the candy out create a situation for employees to learn good or bad behaviors within a work environment. In 
addition, decision-making theory was used as a theoretical framework. Decision-making supports the purposeful process through which action or thought is strategized, implemented, and evaluated (Tarter \& Hoy 1998).

\section{EDM in Poland}

Limited research is available with regard to ethical decision-making and higher education. Even less research is available on ethical decision-making within Polish organizations (to date two articles were found). Past research in Poland only explored moral reasoning as related to Kohlberg's cognitive development and found that the level of education and cognitive ability directly related to the level of moral reasoning (Stewart, Sprinthall, \& Siemienska 1997).

Stewart and colleagues (1997) examined ethical reasoning (also referred to as moral reasoning) first with survey questionnaires and then with focus groups with Polish officials in the fall of 1990. Results were then compared with similar previous studies conducted on U.S. officials. With the fall of Communism and a new government taking over researchers were interested in the ethical decision-making process of newly elected officials and how they compared to U.S. counterparts. The most surprising finding was that Polish officials "in [a] newly democratic Poland paralleled almost precisely their counterparts in the United States, with their distinct preference for law and duty as the basis for decision-making" (Stewart et al. 1997, 449).

However, past views of the Communist regime did affect the view and reasoning of officials: "[We have] bad memories of the Communist regime, when a small group of people had access to government, made decisions, and divided the goods without any social control. Because of that history, we now need to establish transparent and controlled decision-making" (Stewart et al. 1997, 451). In a final observations one participant who was surprised by the results said: "we were taught that the law is not realistic and does not bring justice" (ibid.). Researchers observed that perhaps the process of political maturation was occurring, and therefore, officials were relying on law and duty. This study conflicted with an earlier study on reasoning in which researchers studied a large student group and found a lack of law and duty (Stewart et al.1997). Researchers concluded that only continuous monitoring of the ethical decision-making process throughout time will truly be able to lead to conclusive answers.

During a research study in 2006, Valentine, Godkin, Cyrson, and Fleischman looked at small Polish business owners and operators. A total of 295 surveys were completed and collected by researchers. The survey results revealed that many Polish people's "perceptions of ethical values were negatively related to many of the challenges associated with operating and managing small business" (Valentine et al. 2006, 81). This observation 
suggested that ethical values are a high priority for business people within Poland. Ethical values were further positively related with "getting growth capital" and "absorbing start up losses" which show how the organization may face financial hardships due to all the corruption known to be present within Polish businesses (ibid.). Researchers concluded that training for local business should be grounded in Polish ethical ideologies and not simply mimic those of Western cultures. On the other hand, some of the research did show a strong parallel to American ideologies, and those could be considered for developing ethical standards in Poland. "Polish officials just like their U.S. counterparts, are pulled to law and duty as opposed to principle[s] as the preferred choice in sorting through ethical dilemmas" (Valentine et al. 2006, 82).

Decisions and acts based on values have the potential for social, economic, and political consequences within the higher education context in Poland. Constant pressures and constraints placed on educational leaders offer a unique opportunity to examine decision-making that may positively influence higher education in Poland. Thus, the purpose of a future research investigation would be to first determine the ethical decision-making process and how ethical decision-making is characterized by higher education administrators in Poland, and to examine the environmental factors that influence ethical decision-making.

\section{Methods}

The Delphi Method is a strongly structured group communication process, on which naturally unsure and incomplete knowledge is available and is judged upon by experts (Cuhls 2011). A Delphi study aims to achieve an agreed upon consensus of opinion by conducting two or more rounds of intensive surveys using self-identified "experts" in ethical decision-making by using anonymity and controlled feedback (Clayton 1997). The Delphi Method was selected because it is "structured communication" method among experts which sets future directions for a given topic or field per the opinion of subject-matter experts (Helmer 1975; Loo 2002) in order to "support judgmental or heuristic decision-making, or more colloquially, creative or informed decision-making" (Ziglio 1996, 3). This is the first time in which the Delphi Method is being used to study ethical decision-making.

Using the research questions, three Delphi questions were created for each research question. The type of question was created based on the research question and a review of other Delphi studies for historical reference. A small pilot study was conducted before sending the survey to the subject matter experts (SME). The Delphi Method used SME to define and characterize ethical decision-making of higher education administrators. SMEs then examined and came to consensus about the top environmental 
factors that were believed to influence ethical decision-making. Finally, they synthesized ten pre-identified components from six different established ethical decision-making processes and then used them to build a "new" conceptual model.

\section{Results}

\section{Participants}

Participants the Polish panel was established based on a literature review, review of university departmental faculty pages, and the recommendation of an established tenured ethics professor. A total of 24 participants were identified. Participants were not ranked based on the limited number of available participants; nine participants agreed to participate in the study. There were nine participants for round one, seven participants for round two and six participants for round three of the Delphi Method. Table 3 contains the demographic breakdown of the participants' ages and gender. The majority of participants were 30 years and female.

Table 1: Poland - Demographic characteristics for all three rounds

$\%$ of Sample

\begin{tabular}{llll} 
Variables & Round 1 & Round 2 & Round 3 \\
\hline Age & & & \\
$18-25$ & 56 & 28 & 33.33 \\
$26-30$ & 34 & 43 & 33.33 \\
$36+$ & 10 & 29 & 33.33 \\
Gender & & & \\
Male & 44 & 29 & 50 \\
Female & 56 & 71 & 50 \\
\hline
\end{tabular}

Note: Round $1 \mathrm{~N}=9$, Round $2 \mathrm{~N}=7$, and Round $3 \mathrm{~N}=6$

\section{Results by research question.}

The following are results of the study per each of the research questions. Each research question includes final results and discussion of participant responses.

Research question 1. 
To what extent was there a consensus on a definition of ethical decisionmaking among a Delphi panel of subject matter experts (SMEs) representing leadership in higher education in Poland?

\section{Rounds 1 and 2.}

For the SMEs acknowledged Definitions 5 and 7 as best describing their definition of EDM. No SME from Poland offered any additional feedback or a new definition. The Polish SMEs were asked to rank the two chosen definitions. In Round 2 definition 5 was ranked as the most identifiable. The number 5 EDM definition was:

Making good ethical decisions requires a trained sensitivity to ethical issues and a practiced method for exploring the ethical aspects of a decision and weighing the considerations that should impact our choice of a course of action. Having a method for ethical decision making is absolutely essential. When practiced regularly, the method becomes so familiar that we work through it automatically without consulting the specific steps.

Table 2: Polish definitions descriptive statistics per Round 1

\begin{tabular}{|c|c|c|c|}
\hline & Definition & Mean & S.D. \\
\hline 1. & $\begin{array}{l}\text { A process that must be triggered by the perception } \\
\text { that a given action has a moral or ethical component } \\
\text { that should be evaluated. }\end{array}$ & 2.44 & .87 \\
\hline 2. & $\begin{array}{l}\text { A process that begins with an individual's } \\
\text { recognition that a given action or situation has } \\
\text { ethical content and continues as individuals evaluate } \\
\text { the actions ethically, from behavioral intentions and } \\
\text { engage in actual behavior }\end{array}$ & 2.22 & .97 \\
\hline 3. & $\begin{array}{l}\text { Not a simple and straightforward process but instead } \\
\text { it is complex and multi-dimensional. }\end{array}$ & 2.44 & .88 \\
\hline 4 & $\begin{array}{l}\text { A decision that is both legal and morally acceptable } \\
\text { to the larger community }\end{array}$ & 2.78 & 1.09 \\
\hline 5. & $\begin{array}{l}\text { Making good ethical decisions requires a trained } \\
\text { sensitivity to ethical issues and a practiced method } \\
\text { for exploring the ethical aspects of a decision and } \\
\text { weighing the considerations that should impact our } \\
\text { choice of a course of action. Having a method for } \\
\text { ethical decision making is absolutely essential. When } \\
\text { practiced regularly, the method becomes so familiar } \\
\text { that we work through it automatically without } \\
\text { consulting the specific steps. }\end{array}$ & 1.44 & 1.01 \\
\hline 6. & $\begin{array}{l}\text { An integrative process that is influenced by } \\
\text { counselors' personal character and virtue, cognitive } \\
\text { abilities, and decision-making skills which promotes } \\
\text { sound solutions to ethical dilemmas }\end{array}$ & 2.22 & .83 \\
\hline
\end{tabular}


7. Ethical Decision Making Process is the processes of choosing the best alternative for achieving the best results or outcomes compliance with individual and social values, moral, and regulations.

8. Absolute standard of judgment to a social standard, based on cultural, organizational, or community

9. Rational, deliberate, purposeful action, beginning with the development of a decision strategy and moving through implementation and appraisal of results

Note: $\mathrm{N}=9$

Final round.

In Round 3, definition 5 was also ranked as the most identifiable. General comments that were offered by Polish SMEs in the final round were, "one reservation inserting: I do not share the belief of automatism in making ethical decisions; regardless of the degree of possibility presented within their environment." A different Polish expert said: "Intuition in making moral decisions is important - it is not only defined as a known habit, but also outside known reference of possible ways of proceedings to those acquired within axiological preferences of life." Another SME said:

In addition a person should then take appropriate actions, without a doubt which are tied to relationship that we have with ethics. The mere recognition of ethical issues, which shows that necessity, is interconnected with sensitivity and moral issues of an experience. Decision-making should be remembered, however, that it brings together also dangers, relationship associated with superficial ratings given in any situation.

Table 3: Polish definitions Round 2 and Round 3 - percentage votes

\begin{tabular}{llc}
\hline \multicolumn{1}{c}{ Definition } & $\begin{array}{c}\text { Round } \\
\text { Round 3 } \\
\%\end{array}$ & 1.00 \\
\hline 1. $\begin{array}{l}\text { Making good ethical decisions requires a } \\
\text { trained sensitivity to ethical issues and a } \\
\text { practiced method for exploring the ethical } \\
\text { aspects of a decision and weighing the }\end{array}$ & .90 & \\
considerations that should impact our \\
choice of a course of action. Having a \\
method for ethical decision making is \\
absolutely essential. When practiced \\
regularly, the method becomes so familiar \\
that we work through it automatically \\
without consulting the specific steps.
\end{tabular}


2. Ethical Decision Making Process is the processes of choosing the best alternative for achieving the best results or outcomes compliance with individual and social values, moral, and regulations.

Note: Round $2 \mathrm{~N}=7$; Round $3 \mathrm{~N}=6$. Percentages based on total participants ranking of each definition in Round 3.

Research question 2

Was there consensus on the top environmental factors that they believed important for ethical decision-making among Delphi panel of experts representing leadership in higher education in Poland?

Rounds 1 and 2

Table 4 illustrates environmental factors that were ranked in Round 1 from the Polish experts; a consensus was reached in each round. The list provided is the original list from the research. After translation it was determined that societal values and humanistic values translated to the same word.

Table 4: Environmental factors - descriptive statistics for Polish experts per Round 1

\begin{tabular}{lll}
\hline Environmental Factor & Mean & S.D. \\
\hline Seriousness of consequences & 1.56 & .72 \\
Social consequences & 1.66 & .71 \\
Proximity & 3.11 & .78 \\
Rewards Systems & 2.33 & 1.12 \\
Norms & 1.56 & .53 \\
Codes of Conduct & 1.89 & 1.00 \\
Organizational Climate & 2.22 & .83 \\
Ethical Climate & 1.67 & .50 \\
Magnitude of consequences & 1.44 & .73 \\
Social Consensus & 1.78 & .50 \\
Temporal immediacy & 2.67 & .87 \\
Probability of effect & 2.67 & 1.12 \\
Cultural & 1.78 & .83 \\
Peer Pressure & 2.11 & .78 \\
Management Influence & 2.44 & .53 \\
Organizational Size & 2.78 & .83 \\
Organizational Level & 2.44 & .73 \\
Industry Type & 3.00 & .87 \\
Business Competitiveness & 2.78 & .83 \\
Risk & 1.78 & .83 \\
Opportunity & 2.22 & .83 \\
Sanctions & 2.11 & .78 \\
Societal values & 1.78 & .67 \\
\end{tabular}




\begin{tabular}{lll} 
Corporate goals & 2.38 & 1.01 \\
Stated Policy & 2.44 & 1.01 \\
Corporate culture & 1.89 & .83 \\
Licensing requirements & 2.67 & .78 \\
Professional Meetings & 2.78 & .71 \\
Peer Group & 2.22 & .67 \\
Family & 2.22 & .67 \\
Legislation & 2.22 & .67 \\
Judicial System & 2.11 & 1.09 \\
Taxation & 3.22 & 1.27 \\
Financial Needs & 2.80 & .78 \\
Behavior of Superiors & 2.00 & 1.00 \\
\hline
\end{tabular}

Note: $\mathrm{N}=9$

Final round.

Table 5 illustrates environmental factors that were ranked in rounds 2 and 3 . Final environmental factors that were ranked and agreed upon as most influential by Polish experts are: norms (47\%), social values (22\%), seriousness of consequences (17\%), and ethical climate (14\%). The Polish panel did not provide any further commentary on the selected choices.

Table 5: Environmental factors per Round 2 and Round 3 for Polish SME

\begin{tabular}{lll}
\hline Environmental Factor & Round 2\% & Round 3 \% \\
\hline Norms & .17 & .47 \\
Societal values & .17 & .22 \\
Ethical Climate & .15 & .14 \\
Seriousness of consequences & .09 & .17 \\
Magnitude of Consequences & .06 & -- \\
Social Consensus & .06 & -- \\
Sanctions & .06 & -- \\
Family & .06 & -- \\
Legislation & .06 & -- \\
Codes of Conduct & .03 & -- \\
Cultural & .03 & -- \\
Opportunity & .03 & -- \\
Behavior of Superiors & .03 & -- \\
Social Consequences & .00 & -- \\
Organizational Climate & .00 & -- \\
Peer Pressure & .00 & -- \\
Risk & .00 & --
\end{tabular}




$\begin{array}{lll}\text { Humanistic values } & .00 & -- \\ \text { Corporate culture } & .00 & -- \\ \text { Peer Group } & .00 & -- \\ \text { Judicial System } & .00 & --\end{array}$

Note: Round $2 \mathrm{~N}=7$; Round $3 \mathrm{~N}=6$. Percentages based on total

participants ranking of each definition for Round 3.

Research question 3

Was there consensus among Delphi panel of experts representing leadership in higher education in Poland in identifying and connecting the multiple process components of ethical decision-making models and if no consensus was reached what differences in choices of model components existed?

The Polish expert panel submitted five models. Therefore in Round 2, participants were asked to rank all five models that were submitted. They were asked to rank the models based on the following ranking scale: 1 being the one that best described their ethical decision-making process and 3 being the one that least described their ethical decision-making process. Table 6 shows the results from rounds 2 and 3 for the Polish panel. Component 1 (see Appendix A) was the model with the highest percentage (56\%) after panel experts ranked the models in Round 3. Panel experts justified the choice by saying, "model 1 was less chaotic," or "the component schematic diagram of the first is a better ethical decision-making model because of the multidimensional aspect," and:

It seems to me that, that model 1 best represents the issues of ethical decision-making. Each part allows to subjectively evaluate the ethical problem, which is subject to considerations in many components of decision-making: In the case of decision-making, part of man that is trying to be the best and he's in consideration of his own beliefs as well as the consequences of the resulting influences.

Table 6: Polish component Round 2 and Round 3

\begin{tabular}{lll}
\hline Environmental Factor & Round 2\% & Round 3\% \\
\hline Component 1 & .23 & .56 \\
Component 2 & .23 & .44 \\
Component 3 & .20 & -- \\
Component 4 & .17 & -- \\
Component 5 & .17 & -- \\
\hline
\end{tabular}

Note: Round $2 \mathrm{~N}=7$; Round $3 \mathrm{~N}=6$. Percentages based on total participants ranking of each component for Round 2 and Round 3. 


\section{Conclusions}

The present study was exploratory in nature and was carried out with a group of SMEs in ethics in higher education in Poland in order to: a) define ethical decision-making within higher education in Poland, b) identify environmental factors that were deemed important to ethical decision decision-making, and c) use the Delphi research method to create an ethical decision-making process model applicable for use in higher education in Poland.

\section{Research question 1}

To what extent is ethical decision-making defined/described and is there a consensus by Delphi panel of experts representing leadership in higher education in Poland?

A thorough literature review revealed a lack of consensus on or an agreed upon definition of ethical decision-making. The review of literature resulted in identifying nine different definitions that were then presented to Delphi expert panels. Results suggested that experts can, in fact, come to a consensus about how EDM should be defined. The definition that the Polish SME most identified with was developed by Velesquez et al. in 2009 and published by the Applied Ethics Department at Santa Clara University.

This definition reflects a description of EDM but does not describe the specific process to follow. Experts on the Polish panel made similar remarks in that regardless of the situation people should be trained to recognize and understand ethical issues and have a 'practiced method' for processing the situation in which to impact the course of action. This definition suggested less about the process of EDM and more about how important EDM is and that it should be practiced regularly in a more broad sense.

The results in the present study were not supported by the literature. It can be concluded that further research is needed to understand the differences in ethical decision-making as related to Poland. As stated earlier to be globally effective, leaders must be aware of the similarities and differences across and within cultures that could influence business practices (Resick et al. 2006). Understanding how EDM is defined within each culture is a key step in communicating and developing cross-cultural relationships.

\section{Research question 2}

Is there consensus within a Delphi panel of experts representing leadership in higher education in Poland on the environmental factors that influence ethical decision-making? In regards to environmental factors, the literature provided a list of factors that is considered important, but the expert panels were able to narrow those lists down to select variables that can be further examined in future research studies. The focus of this research was to explore the ethical 
decision-making process and the environmental factors that were identified as important. There was a consensus within the group on environmental factors, the Polish expert group narrowed the list down to four influencers: norms, societal values, ethical climate, and seriousness of consequences. None of these influencers are directly tied to organizational culture but do relate to societal influences. This highlights the transition of a nation that has moved from Communism to a democracy in 1989. The current work force is still within the age range in which the majorities have personal memories and experiences during that period of time.

With regards to the Polish panel the responses correspond to the research of Stewart et al. (1997). During the study, focus groups held after the survey indicated that Polish officials felt strongly about accountability. One respondent said "We always try to act according to very transparent and clearly stated rules." It makes sense that the Polish panel was more aware of societal values and opinions as past research has shown a strong tie with societal views as opposed to organizational or corporate culture because it was often seen as dishonest based on experiences during and coming out of the Communist era (Stewart et al. 1997). The findings support the fact that further research is needed to examine environmental factors. In addition, further research can explore in more depth the environmental factors and why they are so different for each culture.

\section{Research question 3}

Was there consensus among Delphi panel of experts representing leadership in higher education in Poland in identifying and connecting the multiple process components of ethical decision-making models and if no consensus was reached what differences in choices of model components existed?

The Polish expert panel, on the other hand, created a model (see: Appendix A) that is very specific with thought out steps and a clear beginning, middle, and end to the process of ethical decision-making. This is observed to be consistent with Polish culture. Polish citizens given their history and experiences are more direct and to the point. They understand ethical values and have a strong sense of ethics as it relates to survival. The model can be interpreted to show a steady, purposeful, and deliberate process to their actions. The Polish model, is similar to the already established models in the literature in that it has a clear beginning and process to follow.

It can be concluded that further research is needed before any definite conclusions can be drawn. No previous model existed in the literature that related to the higher education discipline in Poland. Now that the model has been created a future study can examine if the model is valid and/or actually reflects the population for which it was meant. 


\section{Implications for Research and Practice}

Poland is still, relatively speaking, newly removed from Communism. Through this research it was observed that citizens still draw on those experiences and are wary of "institutions" as if they still draw from a "communist lens" - which does not mean that they support communism but that the experiences they rely on and use to form new ethical decisions are those from a strict and untrustworthy regime. Only time will tell, as those citizens who lived through communism start to retire and the citizens born in 1989 and after having no direct experiences with communism start to enter the work force, if the ideology of "institutions" will change thus changing the opinions of how ethical decision-making is defined, what environmental factors are important, and what ethical decision-making models are applicable to future administrators.

Finally, not a lot of research exists on ethical decision-making, even less existed on EDM and Poland. The research presented here on the EDM definition and top environmental factors helps grow the "conversation". It also shows that previous research that drew direct parallels and generalizations between the U.S. and Poland need to be more cautious. Distinct differences in ideologies and thought do exist at least in ethical thought. This observation can be applied immediately in practice where organizations are based in the U.S. and expanding business into Poland. Understanding that subtle differences may exist may go a long way for a leader to establish codes of conduct or ethical policy that have meaning to the employee. It has implications for possible teachers who teach or wish to teach both populations and how they manage classroom situations. The possibilities seem endless as these areas are explored with future research. 


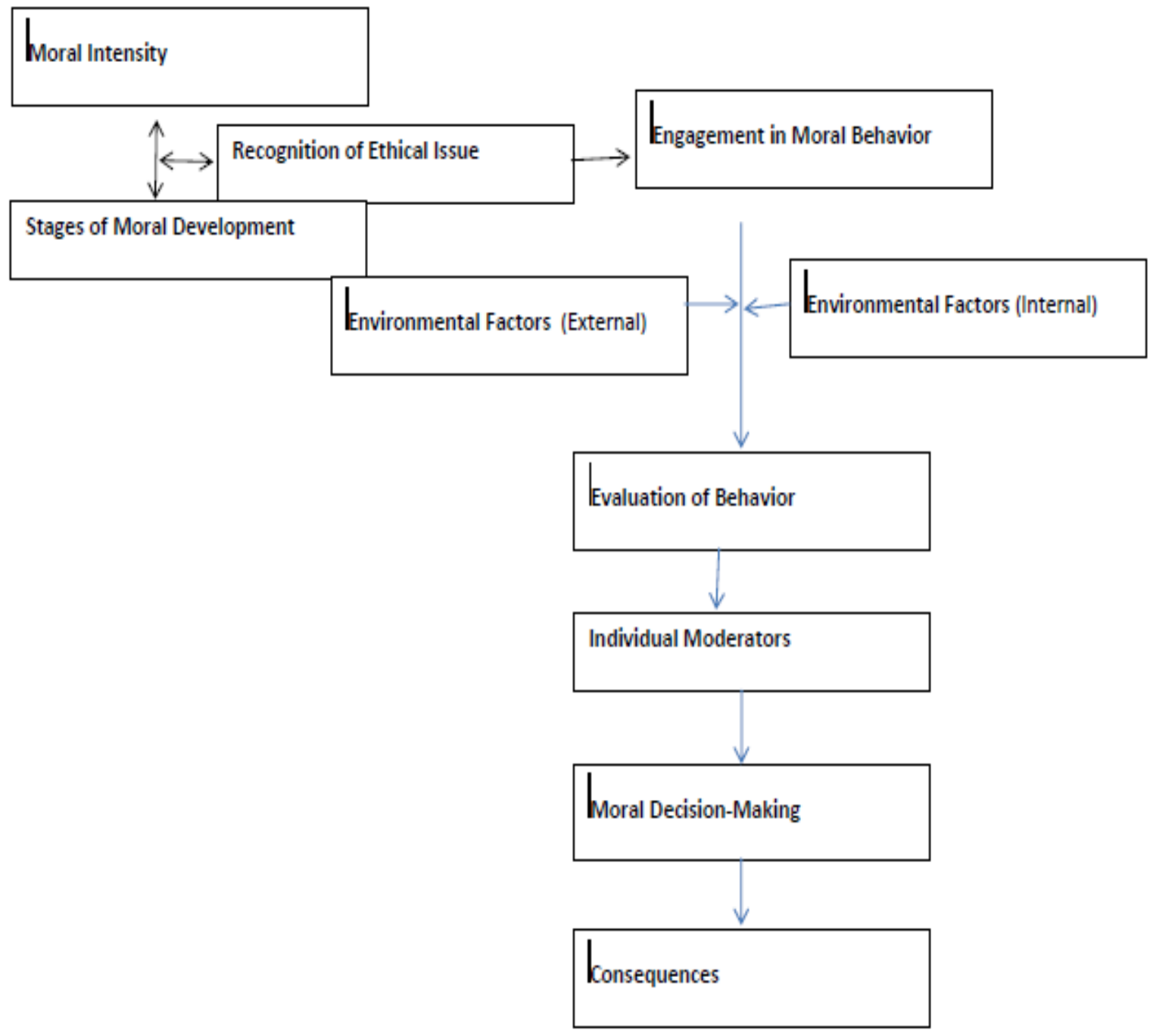

Polish Delphi Expert Ethical Decision Making Model 


\section{References}

Bandura, A. 1977. Social Learning Theory. Upper Saddle River, NJ: PrenticeHall, Inc.

Bartlett, D. 2003. "Management and Business Ethics: A Critique and Integration of Ethical Decision-Making Models." British Journal of Management 14(3): 223-235.

Blank, R. 2012, June 20. Remarks at U.S.-Poland Business Summit Closing. Warsaw: Poland. Retrieved from http://www.commerce.gov/news/acting-secretaryspeeches/2012/06/20/remarks-us-poland-business-summit-closingwarsaw-poland.

Brown, M. E. \& Treviño, L. K. 2006. "Ethical Leadership: A Review and Future Directions." The Leadership Quarterly 7(6): 595-616.

Camp, W. G. 2001. "Formulating and Evaluating Theoretical Frameworks for Career and Technical Education Research." Journal of Vocational Education Research 26(1): 1-13.

Carrithers, M. 1992. Why Humans Have Cultures: Explaining Anthropology and Social Diversity. London: Oxford University Press.

Carroll, A. B. 2004. "Managing Ethically with Global Stakeholders: A Present and Future Challenge." The Academy of Management Executive 18(2): 114-120. Retrieved from http://www.jstor.org/stable/4166070.

Ciulla, J. B. 1998a. Introduction. In Cuilla, J. B. (Ed.), Ethics, the Heart of Leadership. Westport, CT: Quorom Books: xv-xix.

Clayton, M. J. 1997. Delphi: "A Technique to Harness Expert Opinion for Critical Decision-Making Tasks in Education." Educational Psychology 17(4): 373-386.

Cohen, J. R., Pant, L. W., \& Sharp, D. J. 2001. "An Examination of Differences in Ethical Decision-Making Between Canadian Business Students and Accounting Professionals." Journal of Business Ethics 30(4): 319-336.

Creswell, J. W. 2009. Research Design: Qualitative, Quantitative, and Mixed Methods Approaches ( $3^{\text {rd }}$ ed.). Los Angeles, CA: Sage Publications.

Cuhls, K. 2011, October. Delphi Method. Retrieved from United Nations Industrial Development Organization web site: http://www.unido.org/fileadmin/import/16959_DelphiMethod.pdf.

Dubinsky, A. J. \& Loken, B. 1989. "Analyzing Ethical Decision-Making in Marketing." Journal of Business Research 19(2): 83-107.

Ferrell, O. C. \& Gresham, L. G. 1985. "A Contingency Framework for Understanding Ethical Decision-Making in Marketing. Journal of Marketing 49(3): 87-96. Retrieved from http://www.jstor.org/stable/1251618. 
Gladwell, M. 2000. The Tipping Point: How Little Things Can Make a Big Difference. Boston: Little, Brown and Company.

Hatcher, T. \& Aragon, S. R. 2000. "A Code of Ethics and Integrity for HRD Research and Practice." Human Resource Development Quarterly 11(2): 179-185.

Helmer, 0. 1975. "Forward.” In H. Linstone, A. \& Turnoff, M. (Eds.), The Delphi Method: Techniques and Applications. Reading, MA: Addison-Wesley: xix $\mathrm{xx}$.

Hunt, S. D. \& Vitell, S. 1986. "A General Theory of Marketing Ethics.” Journal of Macromarketing 6(1): 5-16.

Jackson, T. 2001. "Cultural Values and Management Ethics: A 10-Nation Study." Human Relations 54(10): 1267-1302. Retrieved from http://hum.sagepub.com/content/54/10/1267.

Jones, T. M. 1991. "Ethical Decision-Making by Individuals in Organizations: An Issue-Contingent Model." The Academy of Management Review 16(2): 366-395. Retrieved from http://jstor.org/stable/258867.

Loo, R. 2002. "The Delphi Method: A Powerful Tool for Strategic Management." Policing 25(4): 762-769.

Martin, G. S., Resick, C. J., Keating, M. A., \& Dickson, M. W. 2009. "Ethical Leadership Across cultures: A Comparative Analysis of German and US Perspectives." Business Ethics: A European Review 18(2): 127-144.

"Poland's Universities in the Red as Student Numbers Decline." 2013, Aug. 30. TheNews. $\quad$ Retrieved from www.thenews.pl/1/12/Artykul/145785,Polands-universities-in-thered-as-student-numbers-decline.

Polish-American Chamber of Commerce of the Southeast United States. 2013, March 6. Retrieved from www.pacc-south.com.

Resick, C. J., Hanges, P. J., Dickson, M. W., \& Mitchelson, J. K. 2006. “A CrossCultural Examination of the Endorsement of Ethical Leadership." Journal of Business Ethics 63(4): 345-359.

Rest, J. R. 1986. Moral Development: Advances in Research and Theory. New York: Praeger.

Schein, E. H. 1990. “Organizational Culture.” American Psychologist 45(2): 109 119.

Sen, A. \& Vinze, A. S. 1997. "Understanding the Complexity of the Model Formulation Process: A Protocol Analysis Approach." Decision Sciences 28(2): 443-473.

Shapiro, J. P. \& Stefkovich, J. A. 2011. Ethical Leadership and Decision-Making in Education: Applying Theoretical Perspectives to Complex Dilemmas (3 ${ }^{\text {rd }}$ ed.). New York: Routledge. 
Sheets, C. A. 2012, October 26. "America Bets on a New European Economic Partner: Poland." International Business Times. Retrieved from http://www.ibtimes.com/america-bets-new-european-economicpartner-poland-852747\#.

Starratt, R. J. 2004. Ethical Leadership (1 ${ }^{\text {st }}$ ed.). San Francisco, CA: Jossey-Bass.

Stewart, D. W., Sprinthall, N., \& Siemienska, R. 1997. "Ethical Reasoning in Time of Revolution: A Study of Local Officials in Poland." Public Administration Review 57(5): 445-453. Retrieved from http://www.jstor.org/stable/3109991.

Tarter, C. J. \& Hoy, W. K. 1998. "Toward a Contingency Theory of DecisionMaking." Journal of Educational Administration 36(3): 212-228.

Thieme, J. K. 2012, June 24. Higher Education Challenges of the 21st Century Poland, Europe, USA [PowerPoint slides]. Retrieved from http://amcham.pl/file/pdf/j_thieme_amcham_bullet_presentation_5_0 3_2009.pdf?PHPSESSID=45caff5e298418b19a7068851714dffa.

Treviño, L. K. 1986. "Ethical Decision-Making in Organizations: A PersonSituation Interactionist Model." The Academy of Management Review 11(3): 601-617. Retrieved from http://www.jstor.org.prox.lib.ncsu.edu/stable/258313.

Treviño, L. K. \& Youngblood, S. A. 1990. "Bad Apples in Bad Barrels: A Casual Analysis of Ethical Decision-Making Behavior.” Journal of Applied Psychology 75(4): 378-385.

Valentine, S., Godkin, L., Cyrson, E. \& Fleischman, G. 2006. "Perceived Ethical Values and Small Business Problems in Poland." Business Ethics: A European Review 15(1): 76-85.

Valentine, S. R. \& Rittenburg, T. L. 2007. "The Ethical Decision-Making of Men and Women Executives in International Business Situations." Journal of Business Ethics 71(2): 125-134.

Ziglio, E. 1996. "The Delphi Method and Its Contribution to Decision-Making.” In Adler, M. \& Ziglio, E. (Eds.), Gazing Into the Oracle: The Delphi Method and Its Application to Social Policy and Public Health. Bristol, UK: Jessica Kingsley Publishers, pp. 3- 33. 


\title{
Tara Shollenberger (High Point, North Carolina)
}

\section{Characterizing Ethical Decision-Making and Its Influences - Examining Higher Education Leaders in Poland}

\begin{abstract}
A review of literature revealed that cross-cultural research had not addressed the topic of ethical decision-making definitions (EDM), environmental factors and EDM models all of which could influence ethical decision-making especially within higher education. The present research study examined ethical decision-making, specifically how it was defined and its process. Then environmental factors were identified by experts as being influential to the process of EDM within higher education in Poland. The research provided focuses mainly on EDM and cultural aspects as related to Poland and higher education. In the conclusion, results were compared to a parallel study that focused on ethical decision-making within higher education in the U.S. This exploratory study used the Delphi research technique to identify an EDM definition that leaders use to make ethical decisions and identify the environmental factors that influence their decisions as well as an EDM model within Poland.
\end{abstract}

Keywords: Higher education, Poland, ethics, ethical decision making, Delphi

Doi: $10.14746 /$ eip.2014.2.10 
